\title{
Corrosion Behavior of 5A05 Aluminum Alloy in NaCl Solution
}

\author{
Bin WANG ${ }^{\dagger}$, Lunwu ZHANG, Yan SU, Yong XIAO and Jie LIU \\ Southwest Technology and Engineering Research Institute, Chongqing Engineering Research Center for Environmen-
} tal Corrosion and Protection, Chongqing 400039, China

[Manuscript received 15 January 2013, in revised form 19 March 2013]

(C) The Chinese Society for Metals and Springer-Verlag Berlin Heidelberg

\begin{abstract}
The corrosion behavior of $5 \mathrm{~A} 05$ aluminum alloy in $3.5 \mathrm{wt} . \% \mathrm{NaCl}$ solution was investigated by scanning electron microscopy (SEM), X-ray photoelectron spectroscopy (XPS), Fourier transform-infrared (FT-IR) spectroscopy and electrochemical impedance spectroscopy (EIS) test, and the corrosion mechanism was also discussed. The results showed that the corrosion rates of the 5A05 alloy were low and decreased with the increase in immersion time. Under the conditions of exposure studied, this alloy suffered from pitting corrosion that took place from or around the intermetallic particles existing in the alloy. The number and size of the hemispherical corrosion pits on the sample surfaces increased with the increase of the test time. The dark-grey layer of corrosion products formed on $5 \mathrm{~A} 05$ aluminum alloy in $3.5 \% \mathrm{NaCl}$ solution contained many microcracks. Furthermore, XPS and FT-IR analysis proved that the corrosion products were mainly composed of $\mathrm{Al}_{2} \mathrm{O}_{3}, \mathrm{Al}(\mathrm{OH})_{3}$ and $\mathrm{AlCl}_{3}$.
\end{abstract}

KEY WORDS: Aluminum alloy; Pitting corrosion; Intermetallics; Electrochemical impedance spectroscopy; X-ray photoelectron spectroscopy

\section{Introduction}

The 5XXX series aluminum (Al) alloys are commonly used in marine applications due to their favorable strength-to-weight property, high thermal conductivity, excellent formability, as well as good corrosion resistance ${ }^{[1,2]}$. It has been acknowledged that corrosion resistance of aluminum alloy depends on formation of a layer of passive film on its surface ${ }^{[3,4]}$. However, when exposed to environments containing halide ions, where the chloride $\left(\mathrm{Cl}^{-}\right)$is the most frequency encountered in service, the oxide film breaks down at specific points leading to the formation of corrosion pits on the aluminum surface. This type of corrosion is known as pitting corrosion ${ }^{[5-8]}$.

On the other hand, alloying elements such as copper, zinc, magnesium and silicon are added to aluminum to improve the mechanical properties. How-

\footnotetext{
† Corresponding author. Ph.D.; Tel.: +86 23 68792022; Fax: +86 23 68792100; E-mail address: wb7411@163.com (Bin WANG)
}

ever, $\mathrm{Mg}$, together with other elements, also precipitates as the bigger intermetallics, which attain high surface densities and are different from the matrix in electrochemical activity ${ }^{[9]}$. Micro-flaws in the oxide film existing at the heterogeneity sites and the potential differences existing between the intermetallic particles and the Al matrix would result in localized attack and enhance the susceptibility of the $\mathrm{Al}$ alloys to pitting corrosion when they are exposed to the solutions containing chloride ions ${ }^{[10,11]}$.

5 A05 alloy is currently used for many engineering applications, however, relatively little work has been done on corrosion behavior for this kind of material and the passivation and corrosion phenomena of which is not fully understood yet. In this study, the electrochemical behavior of this alloy was evaluated in $3.5 \% \mathrm{NaCl}$ solution using EIS technique. The microstructures of the pitting attack of this alloy and the chemical compositions of the corrosion products were also investigated by metallographic microscope, SEM, FT-IR and XPS, and the corrosion mechanism was also discussed. 


\section{Experimental}

\subsection{Materials preparation}

The materials studied were samples of the Al-Mg alloy 5A05, the normal composition (wt.\%) of which

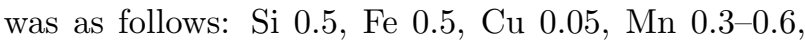
$\mathrm{Mg}$ 4.0-5.5, Zn 0.2, Other 0.1 and Al balanced. Before treated, the sample surfaces were abraded with a series of silicon carbide papers, and then they were washed with distilled water and degreased in acetone and dried. For electrochemical measurements, the metal samples were embedded in epoxy resin, leaving a geometrical surface area of $1 \mathrm{~cm}^{2}$ exposed to the electrolyte.

As the aggressive medium, a solution of $3.5 \% \mathrm{NaCl}$ at $\mathrm{pH} 8.1$ was used. This solution was prepared from analytical grade reagents by dissolving $\mathrm{NaCl}$ in distilled water, and the $\mathrm{pH}$ of the solution was adjusted with a little $\mathrm{NaOH}$.

In order to observe the surface corrosion morphology of the samples, the corrosion products were eliminated by immersing the samples in 70 vol. $\% \mathrm{HNO}_{3}$ solution for $2 \mathrm{~min}$ and then washed with plenty of distilled water.

\subsection{Electrochemical measurement}

The electrochemical measurements were performed using a conventional three-electrode cell at room temperature on PARSTAT 2273 workstation. The cell assembly consisted of $\mathrm{Al}$ alloys as working electrode, a platinum foil as counter electrode, and a saturated calomel electrode (SCE) as a reference electrode with a Luggin capillary bridge. The employed amplitude of the sinusoidal signal was $10 \mathrm{mV}$, and the frequency span $100 \mathrm{kHz}$ to $10 \mathrm{mHz}$. The EIS tests were always conducted from high frequency to low frequency, and ZSimpWin 3.2 software was used for the data fitting of impedance spectra.

\subsection{Surface morphology of the corroded alloys}

The optical microscope studies were conducted with a Nikon Optiphot metallographic microscope equipped with a CCD camera (Sony model Iris) connected to a PC. The samples were mechanically ground down to 1500 grit $\mathrm{SiC}$ paper, polished with $1.5 \mu \mathrm{m}$ diamond paste, then etched in the solution (2 $\mathrm{mL} \mathrm{HF}+3 \mathrm{~mL} \mathrm{HCl}+5 \mathrm{~mL} \mathrm{HNO}_{3}+190 \mathrm{~mL} \mathrm{H} \mathrm{H}_{2} \mathrm{O}$ ) for $20 \mathrm{~s}$ to distinguish the grain boundary for morphology observation.

The SEM studies for the corroded samples with and without corrosion products were conducted with a JEOL 820-SM scanning microscope equipped with a LINK AN-10000 dispersive energy analyzer.

\subsection{Surface analysis}

The corrosion products on sample surfaces were

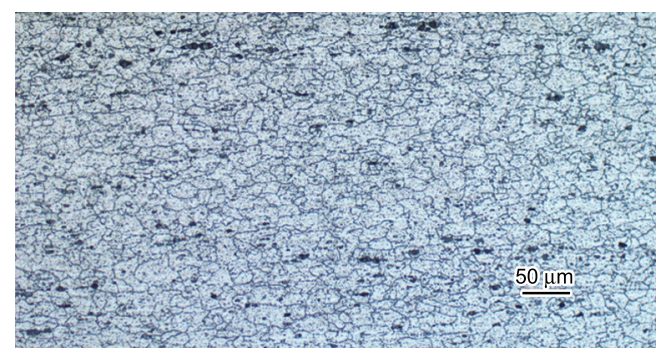

Fig. 1 Optical micrograph of the studied alloy 5A05-O

characterized by means of XPS and FT-IR. XPS spectra were performed with a PHI 5300 spectrometer (Perkin-Elmer, USA) using $\mathrm{Al} K_{\alpha}$ radiation as excitation sources. A take-off angle of $45^{\circ}$ from the surface was employed. All the analyses were performed at a pressure below $1 \times 10^{-8} \mathrm{~Pa}$. Infrared spectra were measured by a VERTEX 70 FT-IR spectrometer (Bruker Optics, Germany) with ATR accessory using a liquid nitrogen cooled mercury-cadmium-tellurium (MCT-A) detector. The OPUS software was used to analyze these spectra.

\section{Results and Discussion}

\subsection{Microstructure examination}

Fig. 1 shows the typical microstructure of 5A05 aluminum alloy under $\mathrm{O}$ heat treatment state. It is observed that the microstructure of $5 \mathrm{~A} 05-\mathrm{O}$ is characterized by irregularly shaped intermetallic particles and their surface distribution is not very homogenous. Such coarse intermetallic particle characteristics have been reported in the literature in which the coarse typical constituents of the 5A05 alloy have been identified to be $\beta\left(\mathrm{Mg}_{5} \mathrm{Al}_{8}\right), \mathrm{Mg}_{2} \mathrm{Si}$ and $(\mathrm{FeMn}) \mathrm{Al}_{6}^{[12]}$. The electrochemical activity associated with these intermetallic particles are different from the matrix, and give rise to localized corrosion phenomena ${ }^{[13]}$.

\subsection{Electrochemical impedance spectroscopy measurement}

The electrochemical response of 5A05 alloy in a solution of $\mathrm{NaCl}$ at $3.5 \%$ has been conducted. The impedance plots obtained for the specimens over different periods are displayed in Fig. 2 in the form of both Nyquist and Bode plots. The plots for 5A05 alloy (Fig. 2(a)) at the soaking time of $0.5,6,12 \mathrm{~h}$ and 1 $\mathrm{d}$ are characterized by two depressed semicircles and there are two time constants visible in bode phase angle plots (Fig. 2(b)). The high frequency semicircle represents the dielectric behavior of the passive film on the base metal while the low frequency spectra corresponds to the metal dissolution process through the defects or pores in the film ${ }^{[14]}$.

The other Nyquist plots in Fig. 2(a) contain a depressed semicircular shape in the complex impedance plane, with the center under the real axis, which is 
Bin WANG et al.: Acta Metall. Sin. (Engl. Lett.), 2013, 26(5), 581-587.

Table 1 Simulative electrochemical parameters obtained by Nyquist plots at different immersion time

\begin{tabular}{ccccccccc}
\hline Time & $\begin{array}{c}R_{\mathrm{s}} \\
(\Omega)\end{array}$ & $\begin{array}{c}(\mathrm{CPE})_{1} \\
\left(\mu \mathrm{F} \cdot \mathrm{cm}^{-2}\right)\end{array}$ & $n_{1}$ & $\begin{array}{c}R_{\mathrm{ct}} \\
\left(\mathrm{k} \Omega \cdot \mathrm{cm}^{2}\right)\end{array}$ & $\begin{array}{c}(\mathrm{CPE})_{2} \\
\left(\mu \mathrm{F} \cdot \mathrm{cm}^{-2}\right)\end{array}$ & $n_{2}$ & $\begin{array}{c}R_{\mathrm{f}} \\
\left(\Omega \cdot \mathrm{cm}^{2}\right)\end{array}$ & $\chi^{2}$ \\
\hline $0.5 \mathrm{~h}$ & 5.787 & 5480 & 0.79 & 0.8 & 490 & 0.89 & 112 & $3.39 \times 10^{-3}$ \\
$6 \mathrm{~h}$ & 5.935 & 4410 & 0.72 & 2.1 & 349 & 0.81 & 378 & $3.12 \times 10^{-3}$ \\
$12 \mathrm{~h}$ & 4.495 & 2470 & 0.72 & 3.7 & 206 & 0.85 & 887 & $2.08 \times 10^{-3}$ \\
$1 \mathrm{~d}$ & 4.734 & 597 & 0.81 & 12.4 & 124 & 0.87 & 5706 & $2.87 \times 10^{-3}$ \\
$2 \mathrm{~d}$ & 4.333 & 59 & 0.92 & 82.1 & 2980 & 0.54 & 57 & $3.21 \times 10^{-3}$ \\
$3 \mathrm{~d}$ & 4.191 & 36 & 0.87 & 138.6 & 670 & 0.64 & 229 & $4.39 \times 10^{-3}$ \\
$4 \mathrm{~d}$ & 5.798 & 30 & 0.75 & 169.1 & 30 & 0.98 & 894 & $6.27 \times 10^{-3}$ \\
$6 \mathrm{~d}$ & 4.236 & 45 & 0.87 & 152.6 & 586 & 0.63 & 424 & $6.03 \times 10^{-3}$ \\
$8 \mathrm{~d}$ & 3.256 & 44 & 0.88 & 132.9 & 566 & 0.63 & 474 & $7.15 \times 10^{-3}$ \\
$11 \mathrm{~d}$ & 5.290 & 37 & 0.86 & 191.1 & 596 & 0.62 & 562 & $5.84 \times 10^{-3}$ \\
$15 \mathrm{~d}$ & 6.083 & 35 & 0.98 & 248.5 & 652 & 0.68 & 196 & $5.36 \times 10^{-3}$ \\
\hline
\end{tabular}
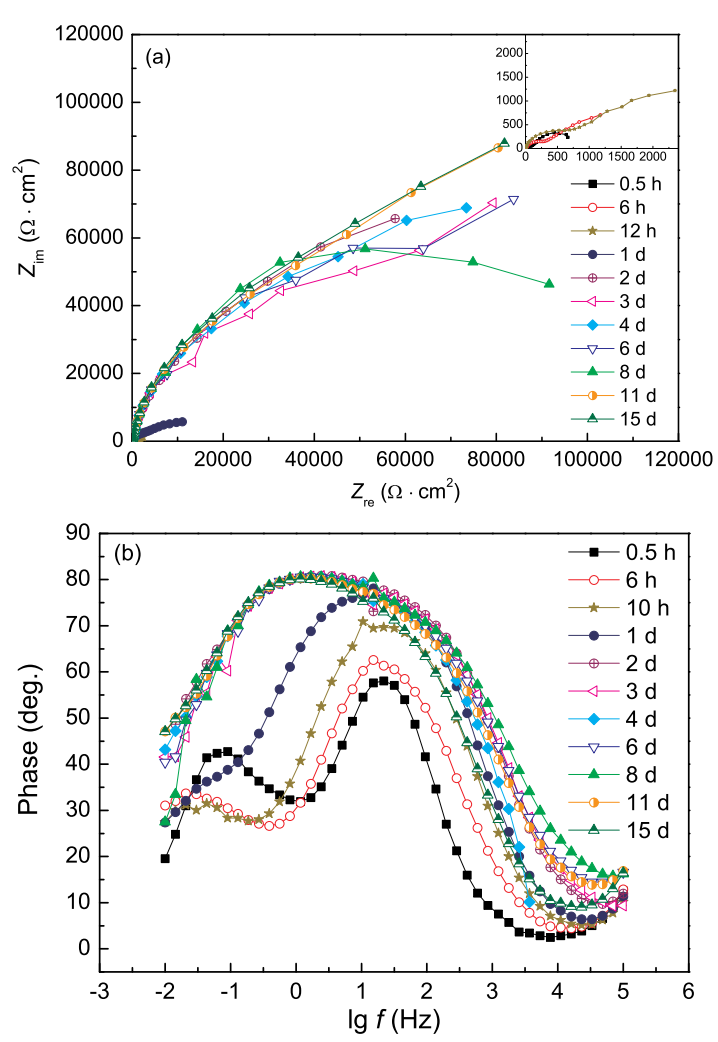

Fig. 2 Impedance spectra for the samples of alloy 5A05 immersed in a solution of $3.5 \% \mathrm{NaCl}$ at different immersion times: (a) Nyquist diagram; (b) Bode diagram

a typical behavior for the solid metal electrodes that show frequency dispersion of the impedance data ${ }^{[15]}$. Dispersion has been attributed to roughness and other inhomogeneities of the solid surface ${ }^{[16,17]}$. The equivalent circuit used to fit the experimental plots is shown in Fig. 3. In the equivalent circuit, $R_{\mathrm{S}}$ is the solution resistance, $R_{\mathrm{f}}$ is the film resistance with constant phase element CPE2 and $R_{\text {ct }}$ is the charge transfer resistance with constant phase element CPE1. Instead of a capacitance, constant phase element (CPE) was used due to the porous and inhomogeneous nature of the film ${ }^{[18]}$. The obtained impedance parameters are summarized in Table 1 . The $\chi^{2}$ is the precision of

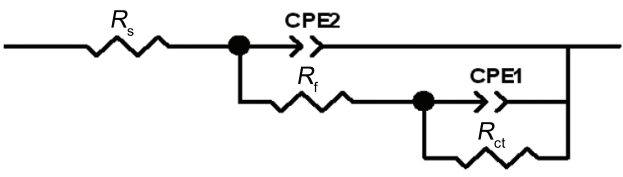

Fig. 3 Corresponding equivalent circuit used in modeling of the electrochemical impedance spectrum data

the simulated data. It can be seen that the $\chi^{2}$ values are small, reflecting the fact that the simulated data have good agreement with the experimental ones.

In this paper, the reciprocal of the charge transfer resistance $\left(R_{\mathrm{ct}}\right)$ is used as a parameter to characterize the corrosion rate. It can be observed from Table 1 that, in general, the $5 \mathrm{~A} 05$ alloy has high $R_{\text {ct }}$ values and they increase gradually with the increase in soaking time, suggesting that the corrosion rates of 5A05 alloy are low and the rates decrease with immersion time. It is also evident from Table 1 that $R_{\mathrm{f}}$ values increase remarkably with immersion time within $1 \mathrm{~d}$ and then the values of which decrease sharply between the soaking time of $1 \mathrm{~d}$ and $2 \mathrm{~d}$, however, after $2 \mathrm{~d}$ of immersion, the values of $R_{\mathrm{f}}$ increase slightly again and then fluctuation of the values is shown. $R_{\mathrm{f}}$ and $(\mathrm{CPE})_{2}$ values have opposite trend at the whole soaking time range. This may be explained by the expression as follows:

$$
C=\varepsilon_{0} \varepsilon s / d^{[19]}
$$

Thus, the increase of $R_{\mathrm{f}}$ with exposure time may indicate that the decrease of $(\mathrm{CPE})_{2}$ of $5 \mathrm{~A} 05$ is basically due to an increase in the thickness of the layer. Accordingly, the decrease of $R_{\mathrm{f}}$ with soaking time suggest that the increase of $(\mathrm{CPE})_{2}$ is due to the decrease in thickness of the passive layer.

\subsection{Micrograph of the corroded alloys without corro- sion products}

SEM images of the samples exposed to $3.5 \% \mathrm{NaCl}$ solution for different test times are shown in Fig. 4. The results show that pitting corrosion can be seen 


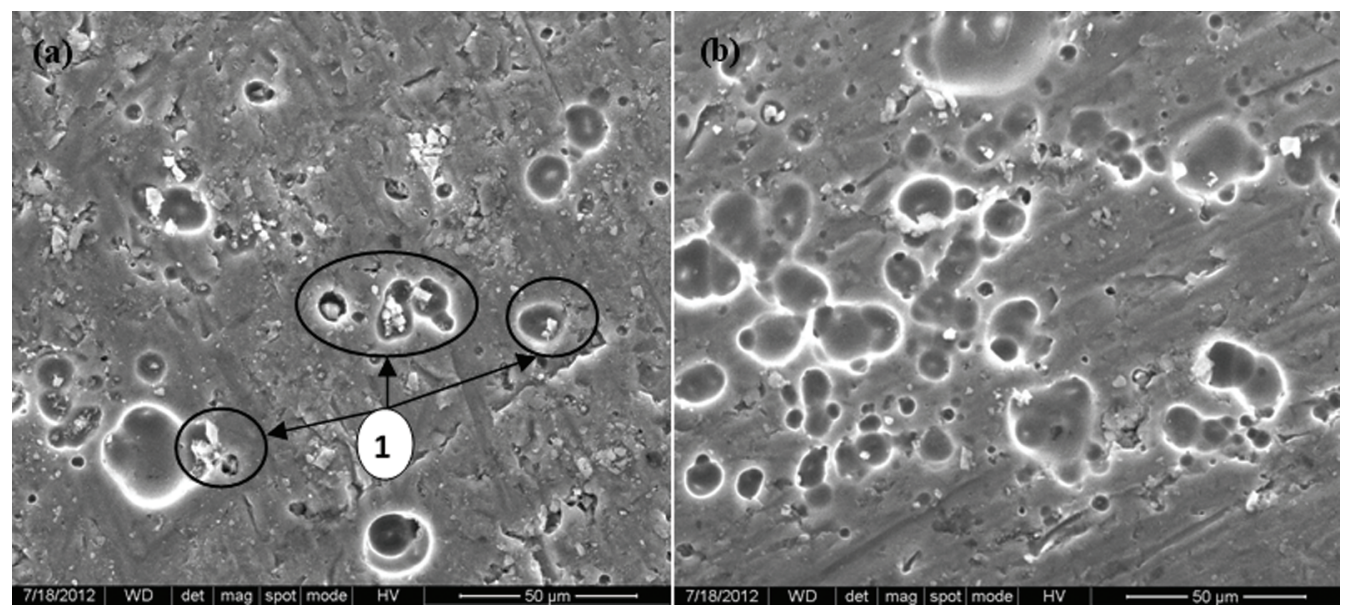

Fig. 4 SEM images of the samples exposed to $3.5 \% \mathrm{NaCl}$ solution for different test time: (a) $1 \mathrm{~d}$; (b) $15 \mathrm{~d}$

easily after test for $1 \mathrm{~d}$ in Fig. 4(a), its number and size increase with the soaking time, after $15 \mathrm{~d}$ of immersion, some corrosion pits have already connected together. Cross-sectional morphology of the specimen was analysed using optical microscope and found that some hemispherical isolated shallow pits occurred on the surface (Fig. 5) of the sample, furthermore, intergranular or exfoliation corrosion were not observed.

The susceptibility of aluminum alloys to pitting corrosion and other forms of localized corrosion is associated with the electrochemical nature of the intermetallic phases. Thus, often its corrosion behavior is correlated with the difference in potential between the matrix and the intermetallic compounds present in the alloy ${ }^{[20-22]}$. Anodic intermetallic particles, such as $\beta\left(\mathrm{Mg}_{5} \mathrm{Al}_{8}\right)$, have been found to be common sites for pits nucleation. In some areas, local dissolution is on the threshold of initiation ${ }^{[23,24]}$. By a different process, Fig. 4(a), marked by 1 , shows the evidence of localized dissolution of the aluminum matrix around intermetallic particles. This observation suggests that these coarse particles, such as $(\mathrm{FeMn}) \mathrm{Al}_{6}$, behave cathodically with respect to the surrounding matrix, which cause the reaction of $\mathrm{O}_{2}$ reduction on top of these precipitates, with the consequent formation of $\mathrm{OH}^{-}$groups. This in turn produces a local increase in $\mathrm{pH}$, which gives rise to the dissolution of the layer of oxide in the area surrounding the precipitate. Once this layer of oxide has been dissolved, the local alkalinization causes an intense attack on the interface between the matrix and precipitate. Additionally, the existence of intermetallic compounds can either promote failures in the protective film of oxide ${ }^{[25-27]}$.

\subsection{Analysis of corrosion products}

Fig. 6 shows the surface morphology of 5A05 sample surface after being corroded for $15 \mathrm{~d}$ in $3.5 \% \mathrm{NaCl}$ solution, it is apparent that the dark-grey layer of corrosion products formed on the specimen surface

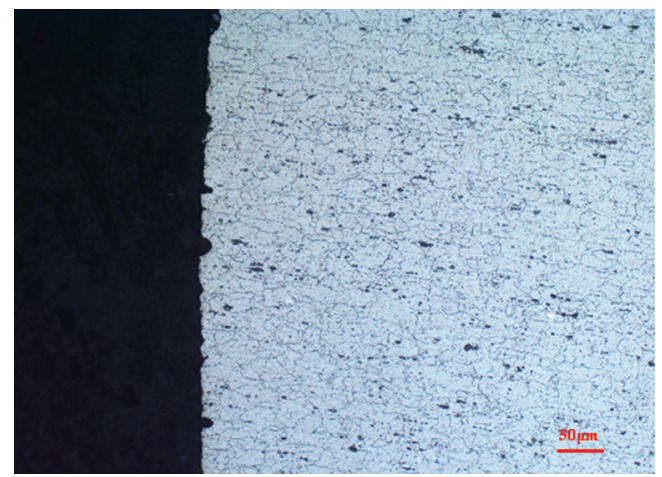

Fig. 5 Cross-section morphology of the pitting on 5A05 alloy after immersed in $3.5 \% \mathrm{NaCl}$ solution for $15 \mathrm{~d}$

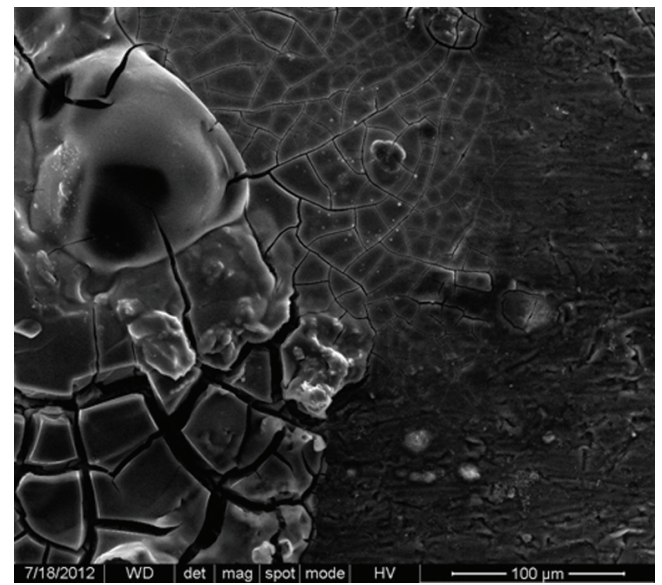

Fig. 6 Surface morphology of 5A05 alloy after immersion for $15 \mathrm{~d}$ in $3.5 \% \mathrm{NaCl}$ solution

contains many microcracks. FT-IR spectroscopy test was performed to characterize the formation of corrosion products on sample surfaces, as shown in Fig. 7. The peaks at 3401,1037 and $898 \mathrm{~cm}^{-1}$ correspond to $\mathrm{Al}(\mathrm{OH})_{3}$ of the corrosion products formed. There are peaks at 1640 and $842 \mathrm{~cm}^{-1}$ due to the formation of 


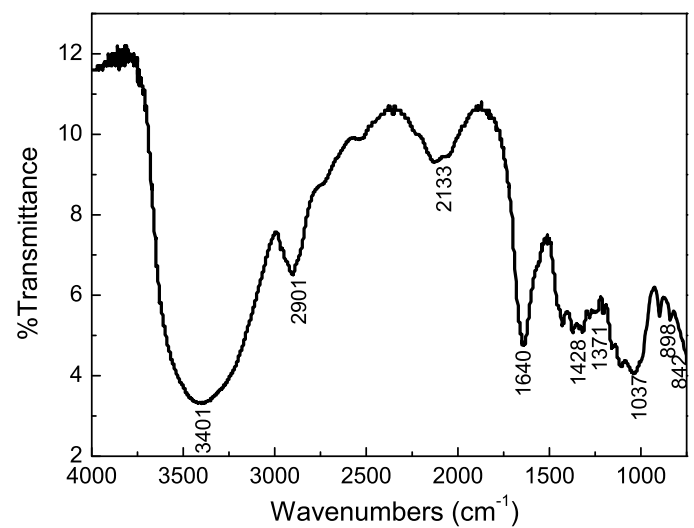

Fig. 7 FT-IR spectrum of corrosion products formed on the sample surface after immersion for $15 \mathrm{~d}$ in $3.5 \% \mathrm{NaCl}$ solution
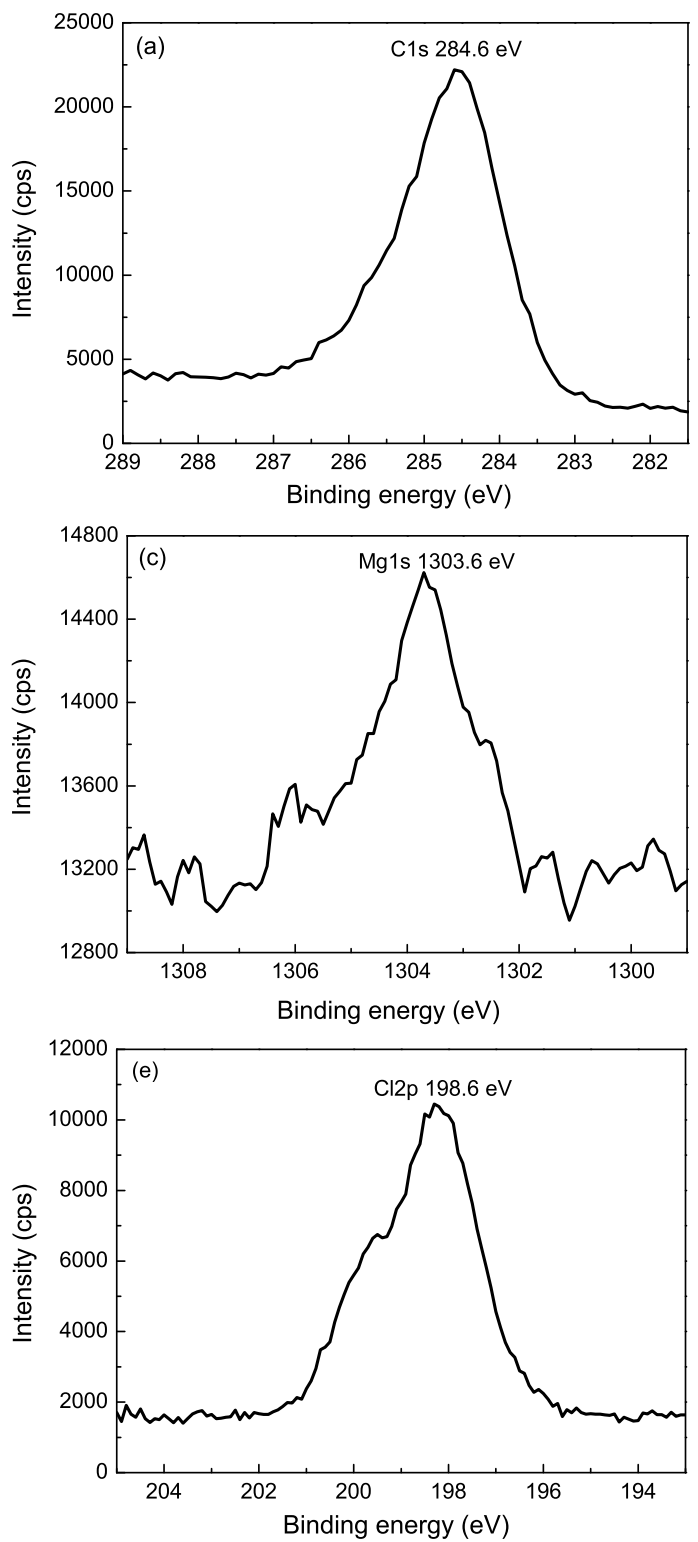

$\mathrm{AlCl}_{3}$. The peaks at 2901 and $1428 \mathrm{~cm}^{-1}$ are very typical characteristic of $\mathrm{Al}_{2} \mathrm{O}_{3}^{[28]}$. So the above results prove that the main component compounds existing in corrosion products formed on 5A05 alloy include $\mathrm{Al}_{2} \mathrm{O}_{3}, \mathrm{Al}(\mathrm{OH})_{3}$ and $\mathrm{AlCl}_{3}$.

In order to obtain more detailed information about the corrosion products, the XPS examination on the surface of the samples was carried out. The XPS results (Fig. 8) indicate that the surface corrosion products contain $\mathrm{C}, \mathrm{Al}, \mathrm{Na}, \mathrm{Mg}, \mathrm{Cl}$, and $\mathrm{O}$ elements. The binding energies are corrected for charge effects by referencing the $\mathrm{C} 1 \mathrm{~s}$ to the peak at $284.6 \mathrm{eV}$. The peak of Na1s is observed at $1071.1 \mathrm{eV}$, which is mainly from $\mathrm{NaCl}$ in the solution. The peaks at 198.6, 531.6 and $1303.6 \mathrm{eV}$ are attributed to $\mathrm{Cl}, \mathrm{O}$ and $\mathrm{Mg}$ elements on the sample surfaces, respectively. XPS spectra carefully considering the binding energies discussed
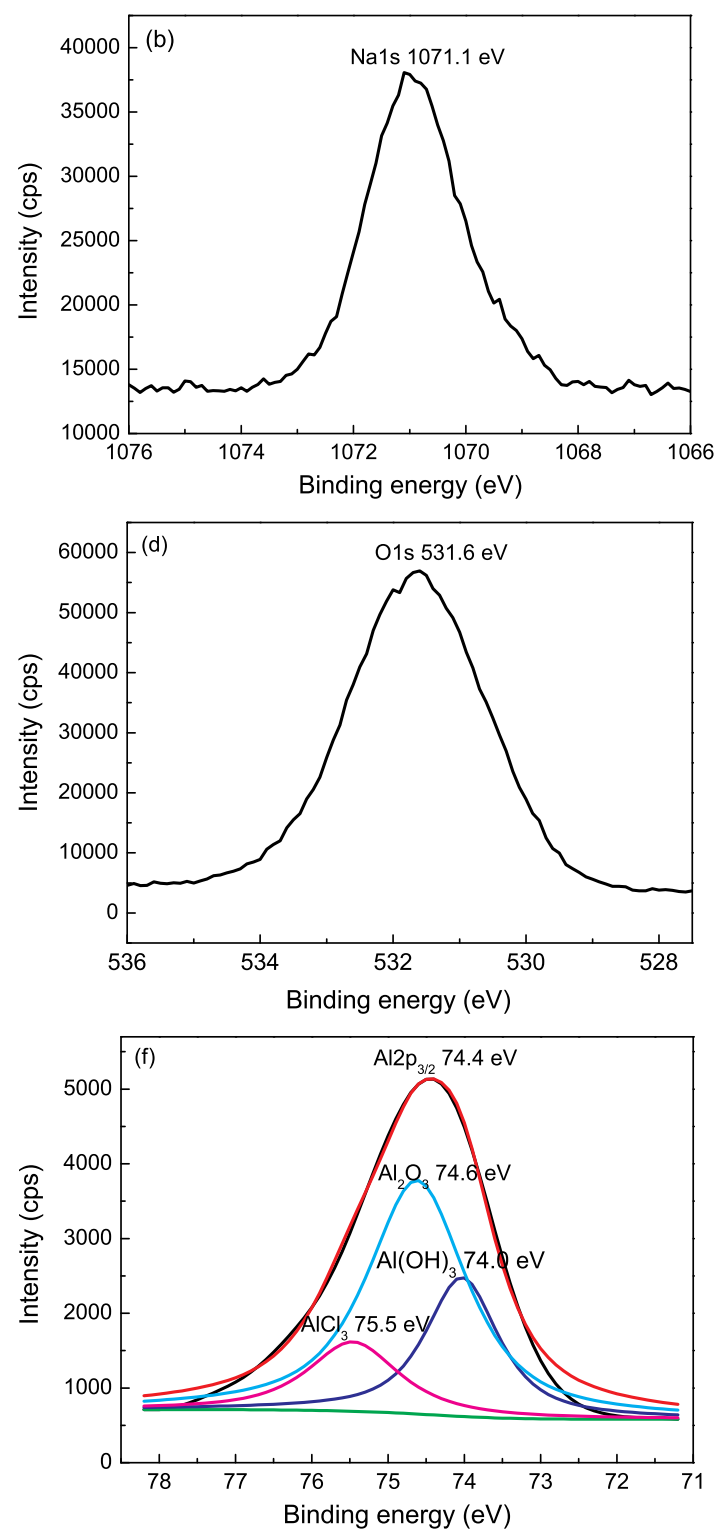

Fig. 8 XPS spectra collected from samples exposed to $3.5 \% \mathrm{NaCl}$ solution for $15 \mathrm{~d}$ : (a) C1s; (b) Na1s; (c) Mg1s; (d) O1s; (e) Cl2p; (f) Al2p 
from $\mathrm{Al} 2 \mathrm{p}$. It can be seen from Fig. 8(f) that the $\mathrm{Al}$ $2 \mathrm{p}$ curves contain complex forms, which are assigned to the corresponding species through a deconvolution fitting procedure, in this way peak identification of characteristic elements is in agreement with suitable databases $^{[29,30]}$. The XPS spectra for Al $2 \mathrm{p}$ display three peaks. The binding energy of the peak at 74.0 $\mathrm{eV}$ can be assigned to $\mathrm{Al}(\mathrm{OH})_{3}$, while the characteristic peaks at 74.6 and $75.5 \mathrm{eV}$ are attributed to $\mathrm{Al}_{2} \mathrm{O}_{3}$ and $\mathrm{AlCl}_{3}$, respectively. The results of $\mathrm{Al} 2 \mathrm{p}$ XPS spectra agree well with the FT-IR analysis.

It is suspected that galvanic cells set up between the intermetallic compounds and the $\mathrm{Al}$ matrix, when a sample of alloy $5 \mathrm{~A} 05$ is exposed to a solution of $\mathrm{NaCl}$, the corrosion of metal is resulted in, with oxidation of $\mathrm{Al}$ alloy as anodic reaction ${ }^{[31]}$ :

$$
\mathrm{Al} \rightarrow \mathrm{Al}^{3+}+3 \mathrm{e}^{-}
$$

Due to acidity at the anodic sites the hydrogen evolution takes palce as a secondary cathodic reaction (in the pit):

$$
2 \mathrm{H}^{+}+2 \mathrm{e}^{-} \rightarrow \mathrm{H}_{2}(\mathrm{~g})
$$

Since the $\mathrm{NaCl}$ solution contains a certain amount of dissolved oxygen, the main cathodic reaction at the cathodic sites (outside the pits) will be the reduction of oxygen:

$$
\mathrm{O}_{2}+2 \mathrm{H}_{2} \mathrm{O}+4 \mathrm{e}^{-} \rightarrow 4 \mathrm{OH}^{-}
$$

As a result of cathodic reactions, the concentration of hydroxide ions increases, so the local $\mathrm{pH}$ becomes more alkaline, the following chemical reaction occurs:

$$
\mathrm{Al}^{3+}+3 \mathrm{OH}^{-} \rightarrow \mathrm{Al}(\mathrm{OH})_{3}
$$

$\mathrm{Al}(\mathrm{OH})_{3}$ would be further transformed into $\mathrm{Al}_{2} \mathrm{O}_{3}$ by

$$
2 \mathrm{Al}(\mathrm{OH})_{3} \rightarrow \mathrm{Al}_{2} \mathrm{O}_{3}+3 \mathrm{H}_{2} \mathrm{O}
$$

It has been generally acknowledged that the presence of chloride ions in environment results in pitting corrosion of $\mathrm{Al}$ alloy. The role of $\mathrm{Cl}^{-}$in pitting processes and its interaction with passive film have been studied extensively, and models have been developed to illustrate pitting corrosion ${ }^{[32-34]}$. In particular, the point defect model (PDM) is a relatively mature model to describe the growth mechanism and kinetics of passive film as well as pit initiation and growth in the presence of $\mathrm{Cl}^{-[35]}$. According to the point defect model, chloride ions would compete with cation vacancies and replace oxygen in the oxide film to form metal chlorine, resulting in degradation of oxide film and initiation of pitting.

Aluminum chloride identified in this work provides proof that chloride ions will react with cation, such as $\mathrm{Al}^{3+}$, to form chloride-containing compound. Mechanisms are proposed to describe the formation of aluminum chloride ${ }^{[36]}$ :

$$
\mathrm{Al}(\mathrm{OH})_{3}+\mathrm{Cl}^{-} \rightarrow \mathrm{Al}(\mathrm{OH})_{2} \mathrm{Cl}+\mathrm{OH}^{-}
$$

$$
\begin{gathered}
\mathrm{Al}(\mathrm{OH})_{2} \mathrm{Cl}+\mathrm{Cl}^{-} \rightarrow \mathrm{Al}(\mathrm{OH}) \mathrm{Cl}_{2}+\mathrm{OH}^{-} \\
\mathrm{Al}(\mathrm{OH}) \mathrm{Cl}_{2}+\mathrm{Cl}^{-} \rightarrow \mathrm{AlCl}_{3}+\mathrm{OH}^{-}
\end{gathered}
$$

Therefore, the corrosion products formed on $5 \mathrm{~A} 05 \mathrm{Al}$ alloy in near-neutral $\mathrm{pH} \mathrm{NaCl}$ solution generally consist of $\mathrm{Al}(\mathrm{OH})_{3}, \mathrm{Al}_{2} \mathrm{O}_{3}$ and $\mathrm{AlCl}_{3}$, as identified in this work.

\section{Conclusions}

From this study of the corrosion behavior of alloy $5 \mathrm{~A} 05$ in $3.5 \% \mathrm{NaCl}$ solution, it can be conducted that, the corrosion rates of this alloy are low and decrease with the increase in soaking time. The main process this alloy undergoes, under the conditions of exposure studied, is related to pitting corrosion that takes place from or around the intermetallic particles existing in the alloy, which results from the difference in potential between the matrix and the intermetallics. The pit morphology shows hemispherical isolated shallow pits on sample surfaces and the number and size of the pits increase with immersion time, and intergranular corrosion, even exfoliation have not been observed. The dark-grey layer of corrosion products formed on the specimen surface contains many microcracks. In addition, FT-IR and XPS analysis demonstrate the surface corrosion products contain $\mathrm{C}, \mathrm{Al}, \mathrm{Na}, \mathrm{Mg}$, $\mathrm{Cl}$, and $\mathrm{O}$ elements and the main component compounds existing in corrosion products include $\mathrm{Al}_{2} \mathrm{O}_{3}$, $\mathrm{Al}(\mathrm{OH})_{3}$ and $\mathrm{AlCl}_{3}$.

\section{REFERENCES}

[1] Y. Zhao, W.B. Xue and H.F. Liu, Acta Phys. Chim. Sin. 27 (2011) 2618. (in Chinese)

[2] H. Li, D.Z. Pan, Z.X. Wang and Z.Q. Zheng, Acta Metall. Sin. 46 (2010) 494. (in Chinese)

[3] X.T. Chang, J.M. Wang, H.B. Shao, J.B. Wang, X.X. Zeng, J.Q. Zhang and C.N. Cao, Acta Phys. Chim. Sin. 24 (2008) 1620. (in Chinese)

[4] Z. Szklarska-Smialowska, Corros. Sci. 41 (1999) 1743.

[5] G. Davis, B. Shaw, B. Rees and M. Ferry, J. Electrochem. Soc. 138 (1993) 3194.

[6] H. Sheng, C.F. Dong, K. Xiao and X.G. Li, Acta Metall. Sin. 48 (2012) 414. (in Chinese)

[7] W. Carrol and C. Breslin, Br. Corros. J. 26 (1991) 255.

[8] R.T. Foley, Corrosion 42 (1986) 277.

[9] A. Davoodi, J. Pan, C. Leygraf and S. Norgren, J. Electrochem. Soc. 155 (2008) 211.

[10] Y.H. Zhang, Z.Q. Zhang, R.E. Sanders and Q. Liu, Acta Metall. Sin. 48 (2010) 351. (in Chinese)

[11] A. Barbucci, G. Cerisola, G. Bruzzone and A. Saccone, Electrochim. Acta 42 (1997) 2369.

[12] M.G. Yan, China Aeronautical Materials Handbook, 2nd ed., China Standard Press, Beijing, 2001, pp. 210218. (in Chinese)

[13] V. Guillaumin and G. Mankowski, Corros. Sci. 41 (1998) 421

[14] H. Wang and R. Akid, Corros. Sci. 49 (2007) 4491.

[15] F.G. Liu, M. Du, J. Zhang and M. Qing, Acta Phys. Chim. Sin. 24 (2008) 138. (in Chinese) 
[16] K.F. Khaled and N. Hackerman, Electrochim. Acta 48 (2003) 2715.

[17] B. Wang, M. Du, J. Zhang and C.J. Gao, Corros. Sci. 53 (2011) 353.

[18] A. Venugopal, R. Panda, S. Manwatkar, K. Sreekumar, L.R. Krishna and G. Sundararan, Trans. Nonferrous Met. Soc. China 22 (2012) 700.

[19] J.B. Bessone, D.R. Salinas, C.E. Mayer, M. Ebert and W.J. Lorenz, Electrochim. Acta 37 (1992) 2283.

[20] M. Bethencourt, F.J. Botana, J.J. Calvino, M. Marcos, J. Perez and M.A. Rodriguez, Mater. Sci. Forum. 289-292 (1998) 567.

[21] A. Alavi and R. Cottis, Corros. Sci. 27 (1987) 443.

[22] J.L. Ma, J.B. Wen, G.X. Li and C.H. Xu, Corros. Sci. 52 (2010) 534.

[23] R.G. Buchheit, R.P. Grant, P.F. Hlava, B. Mckenzie and G.L. Zender, J. Electrochem. Soc. 144 (1997) 2621.

[24] V. Guillaumin and G. Mankowski, Corros. Sci. 42 (2000) 105.

[25] K. Shimizu, G.M. Brown, K. Kobayashi, P. Skeldon, G.E. Thompson and G.C. Wood, Corros. Sci. 40 (1998) 1049.

[26] A. Aballe, M. Bethencourt, F.J. Botana, M.J. Cano and M. Marcos, Corros. Sci. 43 (2001) 1657.

[27] E.V. Koroleva, G.E. Thompson, G. Hollrigl and M.
Bloeck, Corros. Sci. 41 (1999) 1475.

[28] R.A. Nyquist and R.O. Kagel, Infrared spectra of inorganic compounds, Academic Press, New York, 1971, pp.1-18.

[29] J.F. Moulder, W.F. Stickle, P.E. Sobol and K.D. Bomben, Handbook of X-Ray Photoelectron Spectroscopy, Perkin-Elmer Corporation, Norwalk, CT, 1992.

[30] C.D. Wagner, A.V. Naumkin, A. Kraut-Vass, J.W Allison, C.J. Powell and J.R. Rumble, NIST XRay Photoelectron Spectroscopy database, NIST Standard Reference Database 20, Version 3.5, http://srdata.nist.gov/xps/, October 16, 2012.

[31] S. Gudic, I. Smoljko and M. Kliskic, J. Alloys Compd. 505 (2010) 54.

[32] A.R. Mendoza and F. Corvo, Corros. Sci. 42 (2000) 1123.

[33] T.T. Lunt, J.R. Scully, V. Brusamarello, A.S. Mikhailov and J.L. Hudson, J. Electrochem. Soc. 149 (2002) B163.

[34] A.M. Lucente and J.R. Scully, Corros. Sci. 49 (2007) 2351.

[35] D.D. Macdonald, J. Electrochem. Soc. 139 (1992) 3434.

[36] T. Li, X.G. Li, C.F. Dong and Y.F. Cheng, J. Mater. Eng. Perform. 19 (2010) 591. 